\title{
The Visual Field in Chronic Open Angle Glaucoma: The Rate of Change in Different Regions of the Field
}

\author{
COLM O'BRIEN and BERNARD SCHWARTZ
}

Boston, Massachusetts

\begin{abstract}
Summary
Using automated perimetry the distribution of visual field loss in 40 chronic open angle glaucoma eyes (40 patients) was found to be predominantly in the nasal, supranasal, and superotemporal regions. The rate of change of visual field threshold values in seven regions of the field was measured by trend analysis over $44.9 \pm 17.9$ months. Seventeen eyes had a significant rate of field loss in one or more regions of the field with the remaining eyes either showing improvement or stability. Seven of the 17 eyes with significant regional field loss had stable overall fields. The greatest rate of field loss occurred in the temporal and superotemporal regions. The correlation between the mean threshold value of the initial field test and the rate of change of field over time was significant in the temporal region and of borderline significance in the superotemporal region. The relationship was such that the greater the initial threshold value, the greater the subsequent rate of field loss.
\end{abstract}

The use of static testing of the visual field by automated perimetry with resultant digital values allows for a quantitative determination of retinal sensitivity of the visual field. We have developed a statistical computer program (called trend analysis) to assess the rate of progression of the visual field over time in patients that have a minimum of five field examinations. $^{1}$ By plotting the threshold value (decibels-db) versus time (months), we are able to determine changes or trends of the visual field over time. This type of analysis can be applied to the mean threshold values for the whole field, to each point in the visual field, and also to seven selected regions of the visual field. $^{2}$

We have measured the rate of change of the visual field in a group of 40 chronic open angle glaucoma (COAG) patients with localised visual field loss. We have previously presented the rate of change of each point in the visual field. ${ }^{3}$ In this report, we will present data on the baseline threshold values and the subsequent rate of change of the threshold values over time in the different regions of the visual field.

\section{Subjects and Methods}

The criteria for entry to the study were:

(1) a diagnosis of chronic open angle glaucoma, (COAG) i.e., intraocular pressure $\geqslant 21 \mathrm{mmHg}$ on at least two separate clinic visits, open angles on slit lamp gonioscopy, and characteristic glaucomatous optic nerve damage and visual field loss,

(2) follow-up of at least 20 months with a minimum of five visual fields (Octopus, program 31),

From: Department of Ophthalmology, Tufts-New England Medical Centre, Boston, Massachusetts, USA.

Supported in part by grants from the Ainsworth Scholarship, the International Glaucoma Association and the Alcon Research Institute, Fort Worth, Texas.

Correspondence to: Professor Bernard Schwartz, M.D., Ph.D., Department of Ophthalmology, Tufts-New England Medical Centre, 750 Washington Street, NEMC No. 450, Boston, MA 02111, USA. 
(3) best corrected visual acuity of $6 / 12$ or better,

(4) localised visual field loss.

With the help of the computerised visual field database at the Tufts-New England Medical Centre, forty patients were identified that qualified for inclusion, and we randomly selected one eye of each patient for the study. Demographic and clinical information were gathered from the patients' charts.

The visual fields were performed with the Octopus 2000R perimeter (Interzeag, Schlieren, Switzerland) using program 31 and the size 3 stimulus. All patients had been tested with programs seven and 33 prior to the first program 31 visual field included in this study, to become familiar with perimetry and to rule out any learning effect. When a minimum of five program 31 visual fields had been obtained, the rate of change of the visual field was measured by trend analysis. This is a computer software package which helps us to interpret the vast quantity of numerical data of the perimeter printout. ${ }^{1}$ It is a linear regression plot of the mean threshold value $(\mathrm{db})$ of each field test versus time (month).

The slope ( $\mathrm{db} / \mathrm{month})$ of the regression line of this plot is a measure of the direction and rate of change of the field, and allows the clinician to determine the change or stability of the field over time. The trend analysis slope, either positive (indicating improvement) or negative (indicating deterioration), is significant if the Spearman p value of the correlation coefficient of threshold values over time is less than 0.05 (2-tailed test). ${ }^{4}$ This indicates that the slope is statistically different from zero.

A similar type of analysis can be applied not only to the 73 test points of program 31 for the whole field but also to seven selected regions of the field. The seven regions are the nasal, superonasal, inferonasal, central, superotemporal, inferotemporal and temporal. Figure 1 is a map showing the division of the central 30 degrees of the field into seven regions, with the number of test points in each region in parenthesis. The regions were selected according to the studies of Gramer et al..$^{5}$ and Wirthshafter et al. ${ }^{6}$ To rule out the possible influence of the eyelids and the correcting lens on the field, several points on the periphery of the central 30 degrees have been excluded.
These points are designated by an $\mathrm{X}$ in Figure 1.

Non-parametric statistical tests were used to compare the frequency distributions of variables (Mann-Whitney U), and to correlate variables (Spearmann rank coefficient). ${ }^{4}$ A p value (two-tailed) of less than 0.05 was considered as significant, and values between 0.05 and 0.10 were considered as being of borderline significance.

\section{Results}

The mean \pm standard deviation for the follow-up time for the 40 COAG eyes (40 patients) was $44.9 \pm 17.6$ months. The mean intraocular pressure during the study period was $16.7 \pm 2.7 \mathrm{mmHg}$ (range 9.9 to $20.6 \mathrm{mmHg}$ ). All patients were on treatment during the study. Twenty-six eyes had chronic simple glaucoma, ten had glaucoma with the pigmentary dispersion syndrome, ${ }^{7}$ and four had pseudoexfoliation with glaucoma. ${ }^{8}$ The mean number of visual field examination was $12.6 \pm 5.6$ per eye.

The mean rate of change of the whole field for the 40 eyes was $-0.029 \pm 0.035 \mathrm{db} /$ month . Based on the statistical significance of the trend analysis for the slopes of the whole field, ten of the 40 eyes $(25 \%)$ had a significant rate of field loss, two eyes $(5 \%)$ had a significant rate of field improvement, and the 28 eyes $(70 \%)$ with non-significant slopes were judged to have stable fields. Further investigation of the 28 eyes with stable fields showed that seven eyes had a significant rate of field loss in one or more regions of the field (Table I). The ten eyes which had a significant trend of loss of the whole visual field also showed significant loss in some if not all the regions of the field (Table I).

Figure 2 is a representative map of the total number of eyes with a significant rate of field loss per region, plus the mean threshold value of the initial field test and the mean trend analysis slope of these eyes. Figure 3 is a similar representation of the total number of eyes with stable slopes in the regions. This shows that the mean rate of field change in the nasal and superonasal regions is positive, indicating a slight improvement in these regions during the study (Figure 3). On comparing Figures 2 and 3 , the mean threshold value at 


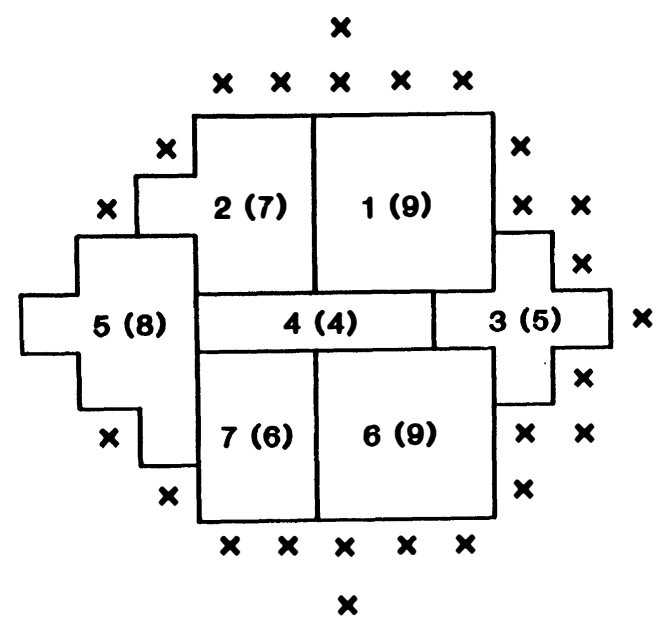

Fig. 1. Central $30^{\circ}$ field (Octopus, program 31) divided into seven regions (right eye) with the number of test points per region in parentheses. Region 1 is superotemporal, region 2 is superonasal, region 3 is temporal, region 4 is central, region 5 is nasal, region 6 is inferotemporal, region 7 is inferonasal. The test points not included in the regions are described by an $X$.

the time of the initial field test is greater in the eyes with significant regional loss than in the eyes with stable regions for all but the inferonasal region. This difference is statistically significant (Mann-Whitney, $\mathrm{p}=0.039$ ) in the superotemporal region, and is of borderline significance $(p=0.089)$ in the temporal region.

Two eyes had a significant improvement of the whole visual field. A further two eyes of the 28 with stable overall fields had a significant improvement in one or more regions of the field.

The threshold value of the initial visual field and the rate of change of threshold values in the regions of the field of the 40 eyes are presented in Table II. The regions most affected

Table I. Number of eyes with a significant rate of visual field loss per region

\begin{tabular}{lcc}
\hline Region & $\begin{array}{l}\text { Stable Total } \\
\text { Field }(\mathrm{n}=28)\end{array}$ & $\begin{array}{l}\text { Losing Total } \\
\text { Field }(\mathrm{n}=10)\end{array}$ \\
\hline Superotemporal & 2 & 7 \\
Superonasal & 2 & 6 \\
Temporal & 0 & 9 \\
Central & 0 & 3 \\
Nasal & 0 & 5 \\
Inferotemporal & 3 & 3 \\
Inferonasal & 0 & 5 \\
\hline
\end{tabular}

by visual field loss, that is the lowest threshold values, at the initial field test were the superonasal, nasal and superotemporal regions, while the least damaged (greatest threshold values) were the central, inferotemporal and inferonasal regions. The greatest rates of field loss were seen in the temporal and superotemporal regions; the least rate of change occurred in the infero- and superonasal regions.

The correlations between the initial threshold value and the rate of field change were found to be negative in all regions, indicating that the greater the initial threshold value the greater the subsequent rate of field loss (Table II). This relationship was significant in the temporal region $(\mathrm{p}=0.011)$ and of borderline significance in the superotemporal region $(\mathrm{p}=0.056)$.

\section{Discussion}

Visual field loss in chronic open angle glaucoma is a combination of diffuse and local changes. ${ }^{9-14}$ Diffuse depression of the retinal light sensitivity is thought to represent diffuse retinal fibre layer loss and a generalised decrease of the neuro-retinal rim area of the optic disc. Localised visual field changes are felt to reflect localised scotomas associated with slit or wedge shaped defects of the retinal nerve fibre layer and localised changes in the neuro-retinal rim. Using automated perimetry, different strategies have been developed to measure these two components of visual field loss. ${ }^{15,16}$ Mean defect (or sensitivity) is a measure of diffuse depression, and corrected loss variance (or pattern standard deviation)

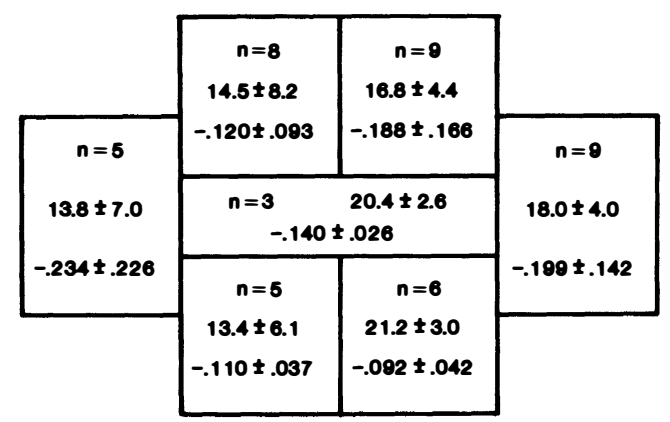

Fig. 2. Map showing the total number of eyes with a significant rate of field loss per region, with the mean threshold value at the initial field test and the mean trend analysis slope of these eyes [Presented as right eyes]. 


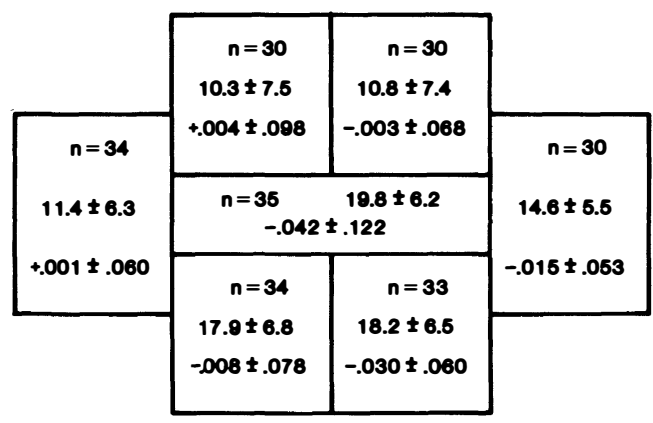

Fig. 3. Map showing the number of eyes with stable fields per region; plus the mean threshold value of the initial field test and the mean trend analysis slope of these eyes [Presented as right eyes].

is a measure of localised defects. More recently, cluster analysis has been used to evaluate further the type of localised field loss. ${ }^{17}$ Diffuse depression of visual field threshold may not truly represent glaucomatous visual field loss. ${ }^{18,19}$

Deterioration of the visual field in chronic open angle glaucoma (COAG) occurs in a variety of ways. ${ }^{20}$ There may be generalised depression of the 'intact' portion of the field, an increase in the size and/or depth of scotomas, or the appearance of new defects. Progression may be gradual or episodic in nature.

In this study, we examined seven regions of the field to determine

(1) the distribution of field loss in COAG,

(2) the rate of field change in different regions of the field using trend analysis,

(3) the relationship between the threshold values of the initial field test and the rate of field change in the regions.

We also wished to determine whether significant regional field loss occurred in the presence of a stable overall field.
Progression of visual field loss can be monitored by statistical tests which are based on changes in the threshold values of the 73 test points over time. ${ }^{1,21-25}$ Because of the considerable amount of fluctuation in thresholds seen from one visual field examination to the next,${ }^{26-29}$ even in patients with stable fields, ${ }^{30} \mathrm{a}$ minimum of four or five field tests are necessary before any meaningful interpretation of the data can be made. The patients in this study had a minimum of five visual field tests and a mean of 12.6 field tests during follow-up. Therefore, changes detected by the trend analysis are felt to reflect true changes in the visual field.

The distribution of field loss in this investigation shows that the superior regions were more involved than the inferior regions, and also that the nasal region was more affected than the temporal region at the time of the initial visual field examination. These findings are in agreement with other studies which used automated perimetry to document visual field loss in open angle glaucoma. ${ }^{31,32}$

Ten eyes were found to have a significant rate of visual field less for the total field and then seven eyes were found to have a significant rate of field loss in at least one or more regions of the field. These seven eyes were part of the group of 28 eyes judged to have stable total fields. Identifying these seven eyes provides evidence of progressive glaucomatous damage and is an indication that further medical or surgical intervention to lower ocular pressure is probably warranted.

Taking the group as a whole, the greatest rate of field loss was seen in the temporal region, followed by the superotemporal region. The least rate of change was seen in the supero- and inferonasal regions. A significant correlation was seen in the temporal

Table II Visual Field Measurements $(n=40)$

\begin{tabular}{lcccc}
\hline & $\begin{array}{c}\text { Mean threshold } \\
\text { value of initial } \\
\text { Field }(\mathrm{db}) \\
\text { (Mean } \pm \text { SD) }\end{array}$ & $\begin{array}{c}\text { Trend Analysis } \\
\text { slope } \\
(\mathrm{db} / \mathrm{month}) \\
\text { Region }\end{array}$ & $\begin{array}{c}\text { Spearman }(\mathrm{r} \text { s) } \\
\text { Correlation } \\
\text { Coefficient }\end{array}$ & $\begin{array}{c}\mathrm{P} \\
\text { Value }\end{array}$ \\
\hline Superotemporal & $12.2 \pm 7.2$ & $-0.041 \pm 0.114$ & -0.304 & 0.056 \\
Superonasal & $11.0 \pm 7.8$ & $-0.018 \pm 0.108$ & -0.025 & NS \\
Temporal & $15.5 \pm 5.3$ & $-0.053 \pm 0.114$ & -0.400 & 0.011 \\
Central & $19.5 \pm 6.1$ & $-0.032 \pm 0.142$ & -0.161 & NS \\
Nasal & $11.6 \pm 6.3$ & $-0.025 \pm 0.122$ & -0.188 & NS \\
Inferotemporal & $18.6 \pm 6.0$ & $-0.031 \pm 0.080$ & -0.192 & NS \\
Inferonasal & $17.6 \pm 6.9$ & $-0.012 \pm 0.099$ & -0.009 & NS \\
\hline
\end{tabular}


region and a borderline significant correlation was obtained in the superotemporal region between the mean threshold value of the initial field test and the rate of change of threshold values. The greater the mean threshold value, the greater the rate of field loss, indicating that the greatest rate of field loss occurs early in the disease.

The mean threshold value of the initial field test in the group of eyes with significant regional field loss was greater than the mean threshold value in the eyes with stable regions in all but the inferonasal region. This provides further evidence that a significant rate of field loss occurs at an earlier stage in the disease process, and confirms previous observations by other investigators. ${ }^{25,33}$

One of the authors (BS) has assigned a copyright received from the United States Government for the Trend Analysis Programs to the Tufts Medical Center Associates, Boston, Massachusetts, USA.

\section{References}

${ }^{1}$ Wu DC, Schwartz B, Nagin P: Trend analyses of automated visual fields. Doc Ophthalmol Proc Soc 1986, 49: 175-9.

${ }^{2}$ Schwartz B and Nagin P: Probability maps for evaluating automated visual fields. In Heijl $A$ and Greve EL (eds). Proceedings of the 6th International visual field symposium, Dordrecht: Dr W. Junk 1985, 39-48.

${ }^{3}$ Araujo D, Schwartz B, Takamoto T, Wu DC, Manning $M$ : The relationship of the rate of change of visual fields to the first visual field. Invest Ophthalmol Vis Sci 1987, (Suppl) 28: 269.

${ }^{4}$ Siegel S: Non-parametric statistics for the behavioural sciences, New York. McGraw-Hill, 1956.

${ }^{5}$ Gramer E, Gerlach R, Kriegelstein GK, Leydhecker W: Zur Topographie früher Glaukomatoser Gesichtsfeldausfalle bei der Computerpermetrie. Klin Monatsbl Augenheilkd 1982, 180: 515-23.

${ }^{6}$ Wirtschaefter JD, Becker WL, Howe JB, Younge BR: Glaucoma visual field analysis by computer profile of nerve fibre function in optic disc sectors. Ophthalmology 1982, 89: 255-67.

${ }^{7}$ Campbell DG: Pigmentary dispersion and glaucoma: A new theory. Arch Ophthalmol 1979, 97: 1667-71.

${ }^{8}$ Prince AM and Ritch R: Clinical signs of the pseudoexfoliation syndrome. Ophthalmology 1986, 93: 803-7.

${ }^{9}$ Airaksinen PJ, Drance SM, Douglas GR, Schulzer M, Wijsman K: Visual field and retinal nerve fibre layer comparisons in glaucoma. Arch Ophthalmol 1985, 103: 205-7.

${ }^{10}$ Drance SM, Airaksinen PJ, Price M, Schulzer M, Douglas GR, Tarsley BW: The correlation of functional and structural measurements in glaucoma patients and normal subjects. Am J Ophthalmol 1986, 102: 612-6.

${ }^{11}$ Glowazki A and Flammer J: Is there a difference between glaucoma patients with rather localised visual field damage and patients with more diffuse visual field damage? Doc Ophthalmol Proc Ser 1987, 49: 317-20.

${ }^{12}$ Caprioli J, Sears M, Miller JM: Patterns of early visual field loss in open angle glaucoma. Am J Ophthalmol 1987, 103: 512-7.

${ }^{13}$ Shiose Y, Iko T, Amaro M, Kawase Y: Relationship between mode of disc cupping and clinical features in primary open angle and low tension glaucoma. Glaucoma 1987, 9: 150-62.

${ }^{14}$ Drance SM, Douglas GR, Airaksinen PJ, Schulzer M, Hitchings RA: Diffuse visual field loss in chronic open angle and low tension glaucoma. Am J Ophthalmol 1987, 104: 577-80.

${ }^{15}$ Flammer J, Drance SM, Augustiny L, Funkhauser A: Quantification of glaucomatous visual field defects with automated perimetry. Invest Ophthalmol Vis Sci 1985, 26: 176-81.

${ }^{16}$ Heijl A, Lindgren G, Olsson J: A package for the statistical analysis of visual fields. Doc Ophthalmol Proc Ser 1987, 49: 153-8.

${ }^{17}$ Chauhan BC, Drance SM, Lai C: A cluster analysis for threshold perimetry. Graefe's Arch Klin Exp Ophthalmol 1989, 227: 216-20.

${ }^{18}$ Longerhorst CT, Van den Berg JJTP, Greve EL: Is there general reduction of sensitivity in glaucoma? Int Ophthalmol 1989, 13: 31-5.

${ }^{19}$ Heijl A: Lack of diffuse loss of differential light sensitivity in early glaucoma. Acta Ophthalmol 1989, 67: 353-60.

${ }^{20}$ Anderson DR: Perimetry: with and without automation. 2nd Edition. St Louis. C. V. Mosby, 1987, 296.

${ }^{21}$ Gloor B, Schmeid U, Fassler A: Changes of glaucomatous field defects, analysis of Octopus fields with programme Delta. Doc Ophthalmol Proc Ser 1981, 26: 11-16.

${ }^{22}$ Holmin C and Krakau CET: Regression analysis of the central visual field in chronic glaucoma cases: A follow-up study using automated perimetry. Acta Ophthalmol 1982, 60: 267-74.

${ }^{23}$ Wilson R, Walker AM, Dueker DK, Crick RP: Risk factors for rate of progression of glaucomatous visual field loss: A computer based analysis. Arch Ophthalmol 1982, 100: 737-41.

${ }^{24}$ Spaeth GL: The effect of change in intraocular pressure on the natural history of glaucoma: Lowering intra ocular pressure in glaucoma can result in improvement of visual fields. Trans Ophthalmol Soc UK 1985, 104: 256-64.

${ }^{25}$ Schultz JS, Werner EB, Krupin T, Bishop KI, Koelle $\mathrm{J}$ : Intraocular pressure and visual field defects after Argon laser trabeculoplasty in chronic open angle glaucoma. Ophthalmology 1987, 94: 553-7.

${ }^{26}$ Flammer J, Drance SM, Zulanf M: Differential light threshold short and long term. fluctuation in patients with glaucoma, normal controls and patients with suspected glaucoma. Arch Ophthalmol 1984, 102: 876-80. 
${ }^{27}$ Gloor BP and Vokt BA: Long-term fluctuations versus actual field loss in glaucoma patients. Dev Ophthalmol 1985, 12: 48-52.

${ }^{28}$ Lewis RA, Johnson CA, Keltner JL, Labermeir PK: Variability of quantitative automated perimetry in normal observers. Ophthalmology 1986, 93: 876-81.

${ }^{29}$ Heijl A, Lindgren G, Olsson J: Normal variability of static perimetric threshold values across the central visual field. Arch Ophthalmol 1987, 105: 1544-9.

${ }^{30}$ Werner EB, Petrig B, Krupin T, Bishop KI: Variability of automated visual fields in clinically stable glaucoma patients. Invest Ophthalmol Vis Sci 1989, 30: 1083-9.

${ }^{31}$ Gramer E, Althaus G, Leydhecker W: Topography and progression of visual field damage in low tènsion glaucoma, open angle glaucoma and pigmentary glaucoma with the program Delta of the Octopus perimeter 201. In Greve EL and Heijl A (eds). Proceedings of the 7th International visual field symposium, Dordrecht: Dr W Junk 1987, 349-63.

${ }^{32}$ Gloor BP, Dimitrakos SA, Rabineau PA: Long-term follow-up of glaucomatous fields by computerised (Octopus) perimetry. In Krieglestein GK (ed). Glaucoma Update III, Heidelberg: Springer-Verlag 1987, 123-38.

${ }^{33}$ Holmin C and Storr-Paulser A: The visual field after trabeculectomy: a follow-up study using computerised perimetry. Acta Ophthalmol 1984, 62: 230-4. 